\title{
Endogenous sex steroids and circulating homocysteine in healthy Greek postmenopausal women. Sex steroids and serum homocysteine
}

\author{
G.E. Christodoulakos ${ }^{1}$, I.V. Lambrinoudaki ${ }^{1}$, D.A. Rizos ${ }^{2}$, A. Alexandrou ${ }^{3}$, \\ A.V. Kountouris ${ }^{1}$, G.C. Creatsas ${ }^{1}$ \\ ${ }^{1} 2^{\text {nd }}$ Department of Obstetrics and Gynecology, University of Athens, Aretaieion Hospital, ${ }^{2}$ Hormonal and \\ Biochemical Laboratory, University of Athens, Aretaieion Hospital, Athens, Greece, ${ }^{3} 2^{\text {nd }}$ Department of Surgery, \\ University of Athens, Laikon Hospital, Athens, Greece
}

\begin{abstract}
OBJECTIVE: The determinants of serum homocysteine in healthy postmenopausal women remain uncertain. The aim of this study was the assessment of the association of endogenous sex steroids with serum homocysteine levels in healthy postmenopausal women not on hormone therapy. DESIGN: 484 postmenopausal women aged 43-69 years were studied in a crosssectional design. Parameters assessed were serum FSH, estradiol, total testosterone, SHBG, Free Androgen Index (FAI), $\Delta 4$-Androstendione $(\Delta 4 \mathrm{~A})$, Dehydroepiandrosterone sulphate (DHEAS) and homocysteine (Hcy). RESULTS: Serum FSH correlated positively $(r=0.23, p=0.01)$, while serum estradiol correlated negatively $(r=-0.25, p=0.03)$ with circulating Hcy. This association remained statistically significant after adjustment for age, years since menopause and BMI. Serum estradiol decreased, while FSH increased linearly with increasing homocysteine quartiles $(p=0.04$ and $p=0.02$, respectively). None of the serum androgens assessed correlated with circulating homocysteine. CONCLUSIONS: Endogenous estrogens and not androgens are related to serum homocysteine values in postmenopausal women. Whether this association has clinical implications remains to be clarified.
\end{abstract}

Key words: Estradiol, Homocysteine, Postmenopausal, Testosterone

\section{INTRODUCTION}

The incidence of cardiovascular disease (CVD) rises after menopause and becomes the principle

Address correspondence and requests for reprints to: Lecturer Irene Lambrinoudaki, 27 Themistokleous Str., Dionysos, GR-14578, Athens, Greece, Tel.: +30-210-6410944, FAX: +30-210-6410325, e-mail: ilambrinoudaki@hotmail.com Received 10-10-05, Revised 23-11-05, Accepted 00-00-05 cause of mortality among postmenopausal women. ${ }^{1}$ Observational studies have suggested that hormone therapy (HT) administered for the relief of climac-

\section{Abbreviations:}

Hormone Therapy: HT, Homocysteine: Hcy, Cardiovascular disease: CVD, Free Androgen Index: FAI, $\Delta 4$-Androstendione: $\Delta 4-A$, Dehydroepiandrosterone sulphate: DHEAS, Years since menopause: YSM, WHI: Women's Health Initiative, HERS: Heart and Estrogen/progestin Replacement Study. 
teric symptoms and urogenital atrophy may be cardioprotective. ${ }^{2,3}$ Possible mechanisms of cardioprotection include favorable modulation of lipids and lipoproteins, ${ }^{4}$ coagulation-fibrinolysis ${ }^{5}$ glucose metabolism, ${ }^{6}$ promotion of vasodilation, ${ }^{4}$ as well as maintenance of vascular endothelial integrity and function $^{7-9}$ and vascular extracellular matrix homeostasis. ${ }^{10}$ However, randomized controlled trials (RCTs) have not confirmed the cardioprotective properties of HT. ${ }^{11,12}$

Homocysteine (Hcy) is a sulfur-containing aminoacid and constitutes a risk factor for vascular damage. Hcy has been associated with CVD as well as with recurrent arterial-venous thromboembolism. ${ }^{13}$ Homozygous or heterozygous defects in genes encoding the enzymes involved in the remethylation (methylene tetrahydrofolate reductase) or transulfuration (cystathionine $\beta$-synthase) metabolic pathways as well as deficiencies in nutrients or micronutrients (folate, vitamins B12 and B6) will disrupt Hcy metabolism and increase circulating Hcy levels. ${ }^{14,15}$ Additionally, Hcy levels may be affected by demographic, lifestyle and various health factors. ${ }^{16}$

Sex steroids appear to influence Hcy metabolism. ${ }^{17}$ Hcy levels are lower in women than in men of comparable age, ${ }^{18}$ and in premenopausal compared to postmenopausal women. ${ }^{17}$ Although Hcy levels increase significantly after menopause, ${ }^{19}$ age cannot be excluded as a confounding factor. ${ }^{20}$ High Hcy levels among postmenopausal women may be associated with an estrogen-depletion mediated effect or with an age-related evolution of Hcy metabolism. ${ }^{20}$ Androgens may also influence Hcy metabolism. Androgens have been reported to increase Hcy levels. ${ }^{21}$ This is of particular importance when HT is considered, especially when the co-administered progestin has an androgenic effect and may modify estrogen's effect on Hcy. ${ }^{22}$ This assumption may be reinforced by the results of the estrogenonly arm of the Women's Health Initiative trial (WHI), which have not indicated an increased risk of estrogen therapy on CVD risk. ${ }^{23}$

In the aftermath of the HERS and WHI trials, researchers and clinicians aim to elucidate further the effect of HT on CVD risk. We considered that it would be of interest to assess the association of Hcy levels with the endogenous estrogen and androgen levels in healthy non-treated postmenopausal women.

\section{METHODS}

\section{Subjects}

Four hundred eighty-four postmenopausal women aged 43-69 years were included in the study. Subjects were recruited from the Menopause Clinic of the $2^{\text {nd }}$ Department of Obstetrics and Gynecology, University of Athens, Aretaieion Hospital. The participants were at least 2 years postmenopausal. All women had not received HT for at least 6 months. None of the participants was under vitamin B supplements

All patients underwent a gynecological and biochemical evaluation which included: bimanual examination, PAP smear and transvaginal sonography, breast examination and mammography, thyroid-liver-renal function as well as blood coagulation tests and bone densitometry. Criteria for inclusion in the study were an endometrial thickness $\leq<=5 \mathrm{~mm}$ and the absence of a history of gynecological malignancy, ischemic heart disease, thromboembolism, diabetes mellitus and non-treated thyroid dysfunction. Ovariectomized women or women taking lipid-lowering or antihypertensive drugs were not included in the study. All subjects signed an informed consent and approval of the Institutional Review Board and of the Ethics Committee of Aretaieion Hospital was obtained.

\section{Protocol}

Participating women were evaluated in a crosssectional design. In every subject a detailed medical history was recorded including regimen and duration of replacement therapy. Blood pressure, weight and height were measured in the morning in light clothing and Body Mass Index (BMI) was computed. Subsequently, fasting blood samples were drawn between 9:00 and 10:00 a.m. for the determination of FSH, estradiol, total testosterone, SHBG, $\triangle 4 \mathrm{~A}$, DHEAS and homocysteine levels. Samples were immediately centrifuged and serum was stored at $-30^{\circ}$ until assayed. 


\section{Hormone assays}

FSH was measured with the Microparticle Enzyme Immunoassay kits: FSH, Abbott Axsym and LH Abbott Axsym, respectively, on Axsym analyzer (Abbott Laboratories, USA). The total coefficient of variation ranged from $5.3 \%$ to $8.5 \%$. Estradiol was measured with the commercial Enzyme Immunoassay kit: DSK-10-4300, Diagnostic Systems Laboratories Inc. The total CV Ranged from 4.3-6.1\% and the sensitivity was $8 \mathrm{pg} / \mathrm{ml}$. $\Delta 4$-Androstendione was measured with the ELISA kit: IBL "Androstendione ELISA" (IBL GmbH, Hamburg, Germany). The interassay \% CV ranged from 6.5 to 8.1. Total Testosterone, DHEAS and SHBG were measured with the DPC kits: "Immulite Total Testosterone", "Immulite DHEA-SO4" and "Immulite SHBG" on Immulite analyzer (Diagnostic Products Corporation, Los Angeles, USA). The total $\% \mathrm{CV}$ ranged from $8.0 \%$ to $16.0 \%, 8.1 \%$ to $15 \%$ and $4.1 \%$ to $9.2 \%$, respectively, as measured in our Laboratory. Free Androgen Index (FAI) was calculated using total testosterone and SHBG values by the following equation: $\mathrm{FAI}=$ testosterone $(\mathrm{ng} / \mathrm{ml}) \times 3.47$ x 100/SHBG (nmol/l). Total Hcy concentrations were measured by the Abbott commercial kit: IMx Homocysteine (Abbott Lab, Abbott Park, IL 60064). The total CV (\%) and the sensitivity were: $4.3 \%$ and $0.5 \mu \mathrm{mol} / \mathrm{l}$, respectively.

\section{Statistics}

Statistical analysis was performed by SPSS Version 11.5 (Statistical Package for the Social Sciences, Chicago, Illinois). Associations between demographic characteristics, serum sex hormones and homocysteine values were assessed by Pearson correlation analysis. Means of continuous variables were compared between groups by the Students- $t$ test for unpaired data. Nominal variables were compared between groups by the chi-square test. Adjustments for possible confounding factors were performed by Analysis of Covariance (ANCOVA). Statistical significance was set at the 0.05 level.

\section{RESULTS}

Demographic characteristics as well as mean levels of serum Hcy and sex hormones of the 484 women participating in the study are presented in Table
1. Estradiol, testosterone and FAI were not normally distributed and thus were logarithmically transformed for further processing.

Mean levels of serum Hcy according to lifestyle factors and family history of CVD are presented in Table 2. Current smokers versus non-smokers and women with a family history of CVD versus those without a family history of CVD tended to have higher serum Hcy levels, but these differences are suggestive ( $\mathrm{p}=0.08$ and $\mathrm{p}=0.09$, respectively). Alcohol intake and physical exercise did not associate with serum Hcy $(p>0.20)$.

Correlation coefficients between serum Hcy and age, years since menopause (YSM), BMI and sex hormones are presented in Table 3. Serum FSH correlated positively and serum estradiol negatively with circulating $\mathrm{Hcy}(\mathrm{r}=0.23, \mathrm{p}=0.01$ and $\mathrm{r}=-0.27$, $\mathrm{p}=0.02$, respectively). This association persisted after adjustment for age, YSM and BMI. Serum FSH increased, while serum estradiol decreased linearly with increasing Hcy quartiles (Figure 1). Circulating Hcy did not associate with any of the androgens assessed (Table 3).

\section{DISCUSSION}

In this study estrogen levels among non-treated postmenopausal women correlated inversely, while serum FSH correlated positively with Hcy levels. No association between Hcy levels and the androgen levels was disclosed.

Sex steroids may be important in modulating Hcy metabolism. ${ }^{24}$ Hcy levels appear to relate to the estrogen status of woman and to the phases of the menstrual cycle. ${ }^{25}$ It has been reported that Hcy is lower in premenopausal as compared to postmenopausal women ${ }^{24}$ and to increase significantly following menopause. ${ }^{19,26}$ Other investigators, however have not reported a menopause-related influence on Hcy levels..$^{20,27,28}$ Furthermore, it is still unclear whether the higher postmenopausal Hcy levels detected in certain studies are related to an effect of estrogen deficiency on Hcy metabolism ${ }^{27}$ or to an age-related disruption in the remethylation and transsulfuration metabolic pathways. ${ }^{24,26}$ In a previous paper $^{20}$ we reported that Hcy increase in post- 
Table 1. Baseline demographic characteristics and hormone levels of the 484 healthy postmenopausal women included in the study.

\begin{tabular}{lccc}
\hline Numeric Variables & Mean \pm SD & Min & Max \\
\hline Age (years) & $55.3 \pm 5.6$ & 43 & 69 \\
Years since menopause (YSM) & $5.6 \pm 5.4$ & 2 & 19 \\
BMI $(\mathrm{Kg} / \mathrm{m} 2)$ & $25.4 \pm 3.6$ & 17.6 & 40.6 \\
FSH $(\mathrm{mIU} / \mathrm{ml})$ & $69.4 \pm 28.8$ & 21 & 168 \\
Estradiol $(\mathrm{pg} / \mathrm{ml})$ & $14.9^{* *} \pm 8.2$ & $<8^{*}$ & 36 \\
Testosterone $(\mathrm{ng} / \mathrm{ml})$ & $0.60^{* *} \pm 0.51$ & $<0.2^{*}$ & 2.8 \\
Free androgen index $(\mathrm{FAI})$ & $2.9^{* *} \pm 3.1$ & 0.2 & 12.3 \\
$\Delta 4 \mathrm{~A}(\mathrm{ng} / \mathrm{dl})$ & $104 \pm 48$ & 11 & 355 \\
DHEAS (ng/ml) & $912 \pm 439$ & 105 & 2510 \\
Homocysteine $(\mu \mathrm{mol} / \mathrm{l})$ & $10.8 \pm 3.3$ & 5.5 & 26.0 \\
Nominal variables & $\mathrm{N}(\%)$ & & \\
Current smoking $(>10$ cigarettes/day) & $117(24.2)$ & & \\
Physical exercise $(>3 \mathrm{~h} /$ week $)$ & $90(18.6)$ & & \\
Daily alcohol intake $(>12 \mathrm{~g} /$ day $)$ & $13(2.7)$ & & \\
Family history of CVD $\left(1^{\text {st }}\right.$ degree relative $)$ & $107(22.1)$ & & \\
\hline
\end{tabular}

(To convert: testosterone from $\mathrm{ng} / \mathrm{dl}$ to $\mathrm{nmol} / \mathrm{L}$, estradiol from $\mathrm{pg} / \mathrm{ml}$ to $\mathrm{pmol} / \mathrm{L}, \Delta 4$ Androstendion from $\mathrm{ng} / \mathrm{ml}$ to $\mathrm{nmol} / \mathrm{L}$ and $\mathrm{DH}$ EAS from $\mu \mathrm{g} / \mathrm{dl}$ to $\mu \mathrm{mol} / \mathrm{L}$ please multiply by conversion factor $0.0347,3.67,0.0349$ and 0.00272 respectively)

* undetectable values

**median values are presented due to skewed distribution

Table 2. Mean (SD) serum homocysteine levels ( $\mu \mathrm{mol} / \mathrm{l}$ ) according to lifestyle factors and family history of cardiovascular disease in the 484 healthy postmenopausal women: Comparisons between the groups (Yes or No).

\begin{tabular}{lcccc}
\hline \multicolumn{1}{c}{ Homocysteine levels } & Mean (SD) & & Mean (SD) & p* \\
\hline $\begin{array}{l}\text { Current smoking (>10 cigarettes/day) } \\
\text { Yes (n=117) vs No (n=367) }\end{array}$ & $11.0(3.5)$ & vs & $10.2(3.2)$ & 0.08 \\
$\begin{array}{l}\text { Physical exercise (>3h/week) } \\
\text { Yes (n=90) vs No (n=394) }\end{array}$ & $11.0(3.7)$ & vs & $10.6(3.1)$ & 0.23 \\
$\begin{array}{l}\text { Daily alcohol intake }(>12 \mathrm{~g} / \text { day) } \\
\text { Yes (n=13) vs No (n=471) }\end{array}$ & $10.9(2.9)$ & vs & $10.7(3.6)$ & 0.56 \\
$\begin{array}{l}\text { Family history of CVD }\left(1^{\text {st }} \text { degree relative) }\right. \\
\text { Yes (n=107) vs No (n=377) }\end{array}$ & $10.8(2.7)$ & vs & $10.2(3.0)$ & 0.09 \\
\hline
\end{tabular}

*p: students t-test for unpaired observations.

menopausal women appears to be age-related; Hcy levels were similar to those reported for premenopausal women, remained unchanged until the age of 60 years, fluctuating around $10 \mu \mathrm{mol} / \mathrm{l}$, and increased significantly in women older than 65 years.

In the present study endogenous estrogen status seems to influence circulating Hcy in postmenopaus- al women, as indicated by both FSH and estradiol associations. The inverse correlation between Hcy and estrogen levels, as well as the positive correlation between Hcy and FSH, most likely indicate that HT administration would decrease circulating Hcy in postmenopausal women. With the exception of one RCT reported by Van Baal et al, ${ }^{29}$ evidence of 


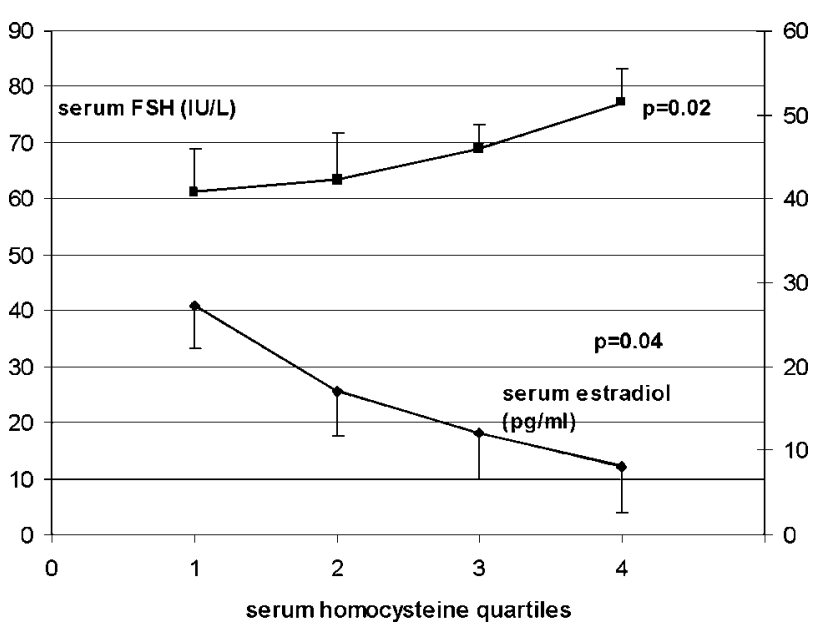

Figure 1. Mean serum FSH (IU/L) and estradiol (pg/ml) in 484 postmenopausal women not on hormone therapy according to serum homocysteine quartiles. p values from ANOVA test for linear trend.

Table 3. Pearson simple and partial correlation coefficients between serum homocysteine and sex steroids.

\begin{tabular}{lcccc}
\hline Variable & $\mathbf{r}$ & $\mathbf{p}$ & partial r & $\mathbf{p}^{*}$ \\
\hline Age (years) & 0.18 & 0.048 & - & - \\
Years since menopause (YSM) & 0.10 & 0.17 & - & - \\
BMI (Kg/m2) & 0.09 & 0.56 & - & - \\
FSH (mIU/ml) & 0.23 & 0.01 & 0.19 & 0.03 \\
Estradiol (pg/ml)** & -0.27 & 0.02 & -0.20 & 0.04 \\
Testosterone (ng/ml)** & 0.07 & 0.44 & 0.06 & 0.39 \\
FAI** & 0.12 & 0.17 & 0.09 & 0.26 \\
$\Delta 4 A(\mathrm{ng} / \mathrm{dl})$ & -0.11 & 0.13 & -0.04 & 0.25 \\
DHEAS (ng/dl) & -0.09 & 0.12 & -0.07 & 0.36 \\
\hline
\end{tabular}

* p values after adjustment for age, YSM and BMI

(To convert: testosterone from $\mathrm{ng} / \mathrm{dl}$ to $\mathrm{nmol} / \mathrm{L}$, estradiol from $\mathrm{pg} / \mathrm{ml}$ to $\mathrm{pmol} / \mathrm{L}, \Delta 4$ Androstendion from $\mathrm{ng} / \mathrm{ml}$ to $\mathrm{nmol} / \mathrm{L}$ and DHEAS from $\mu \mathrm{g} / \mathrm{dl}$ to $\mu \mathrm{mol} / \mathrm{L}$, please multiply by conversion factor $0.0347,3.67,0.0349$ and 0.00272 , respectively)

** logarithmically transformed due to skewed distribution

HT-related decrease of Hcy is based on observational studies. However, two observational studies, those of Evio et $\mathrm{al}^{30}$ and Cagnaci et $\mathrm{al},{ }^{22}$ both evaluating the effect of 17E2+NETA, and one RCT by Smolders $^{31}$ evaluating $17 \mathrm{bE} 2+$ gestodene, have failed to show a significant decrease in circulating Hcy. No consensus can be drawn from the litera- ture regarding the effect of transdermal HT administration. An observational study ${ }^{30}$ and a recent $\mathrm{RCT}^{31}$ have reported no effect of estrogens on Hcy, while two observational studies ${ }^{22,32}$ associated transdermal HT with a significant Hcy decrease. We cannot, therefore, draw any firm conclusion either on the effect of estrogens on Hcy or the possible role of hepatic metabolism in modulating Hcy levels. ${ }^{18}$

No study has yet elucidated the role of progestin in the combined HT. Progestins, depending on their chemical structure, may enhance, attenuate or even reverse estrogen's effect. Androgenic progestins are known to modify the lipids profile. ${ }^{33}$ Mijatovic et al ${ }^{34}$ and $\mathrm{Van} \mathrm{Baal}^{29}$ investigating dydrogesterone and trimegestone, respectively, reported that these progestins potentiate estrogen's lowering effect on Hcy, while Evio $^{30}$ attributed the absence of an effect to the presence of NETA. However, of five studies $^{22,30,35-37}$ investigating the effect of E2 + NETA on Hcy, only one ${ }^{30}$ did not demonstrate a decreasing effect. A more precise methodology, as suggested by Lobo, ${ }^{17}$ could possibly clarify the role of the progestin.

In the present study DHEAS, $\Delta 4 \mathrm{~A}$, testosterone as well as FAI were not related with serum Hcy. Hcy levels are reported to be higher in men than in women of comparable age, ${ }^{38}$ increase in female-tomale transsexuals treated with androgens and decrease in male-to-female transsexuals treated with estrogens. ${ }^{21}$ The absence of association between androgens and Hcy, seen in our study, does not favor the assuption that androgenic progestins may antagonize the estrogen-dependent decrease in homocysteine.

The results of our study show that estrogen levels and not androgen levels relate to Hcy values. If indeed increased estrogen levels associate with decreased Hcy, then it is logical to assume that HT given to symptomatic women in menopause of recent onset might modulate favorably cardiovascular risk. However, it remains to be proven whether lowering Hcy levels is associated with a lower cardiovascular risk. To date, no study has investigated whether the decrease in Hcy levels by HT translates clinically to cardiovascular risk reduction. 


\section{REFERENCES}

1. Colditz GA, Willett WC, Stampfer MJ, Rosner B, Speizer FE, Hennekens C, 1987 Menopause and the risk of coronary heart disease in women. N Engl J Med 316: 1105-1110.

2. Mendelsohn ME, Karas RH, 1999 The protective effects of estrogen on the cardiovascular system. N Engl J Med 340: 1801-1811.

3. Grodstein F, Manson JE, Colditz GA, Willett WC, Speizer FE, Stampfer MJ, 2000 A prospective, observational study of postmenopausal hormone therapy and primary prevention of cardiovascular disease. Ann Intern Med 133: 933-941.

4. Nasr A, Breckwoldt M, 1998 Estrogen replacement therapy and cardiovascular protection: lipid mechanisms are the tip of an iceberg. Gynecol Endocrinol 12: 43-59.

5. Lip GY, Blann AD, Jones AF, Beevers DG, 1997 Effects of hormone-replacement therapy on hemostatic factors, lipid factors, and endothelial function in women undergoing surgical menopause: implications for prevention of atherosclerosis. Am Heart J 134: 764771.

6. Stevenson JC, Oladipo A, Manassiev N, Whitehead MI, Guilford S, Proudler AJ, 2004 Randomized trial of effect of transdermal continuous combined hormone replacement therapy on cardiovascular risk markers. Br J Haematol 124: 802-808.

7. Ylikorkala O, Cacciatore B, Paakkari I, Tikkanen MJ, Viinikka L, Toivonen J, 1998 The long-term effects of oral and transdermal postmenopausal hormone replacement therapy on nitric oxide, endothelin-1, prostacyclin, and thromboxane. Fertil Steril 69: 883-888.

8. Farzati A, Esposito K, Colacurci N, Fornaro F, Chiantera V, Farzati B, 2002 Effects of transdermal hormone replacement therapy on levels of soluble P- and E-selectin in postmenopausal healthy women. Fertil Steril 77: 476-480.

9. Christodoulakos G, Lambrinoudaki I, Panoulis C, Papadias C, Economou E, Creatsas G, 2004 Effect of hormone therapy and raloxifene on serum VE-cadherin in postmenopausal women. Fertil Steril 82: 634638.

10. Zanger D, Yang BK, Ardans J, et al, 2002 Divergent effects of hormone therapy on serum markers of inflammation in postmenopausal women with coronary artery disease. J Am Coll Cardiol 36: 1797-1802.

11. Hulley S, Grady D, Bush T, et al, 1998 Randomized trial of estrogen plus progestin for secondary prevention of coronary heart disease in postmenopausal women: Heart and Estrogen/progestin Replacement Study (HERS) Research Group. JAMA 280: 605-613.

12. The Writing Group for the Women's Health Initiative investigators. (Year ? ) Risks and benefits of estrogen plus progestin in healthy postmenopausal women.
JAMA 288: 321-333.

13. Smolders RG, van der Mooren MJ, Sipkema P, Kenemans P, 2003 Estrogens, homocysteine, vasodilatation and menopause: basic mechanisms, interactions and clinical implications. Gynecol Endocrinol 17: 339-354.

14. Jacobsen DW, 1998 Homocysteine and vitamins in cardiovascular disease. Clin Chem 44: 1833-1843.

15. Jacques PF, Selhub J, Bostom AG, Wilson PW, Rosenberg IH, 1999 The effect of folic acid fortification on plasma folate and total homocysteine concentrations. N Engl J Med 340: 1449-1454.

16. Strassburg A, Krems C, Luhrmann PM, Hartmann B, Neuhauser-Berthold M, 2004 Effect of age on plasma homocysteine concentrations in young and elderly subjects considering serum vitamin concentrations and different lifestyle factors. Int J Vitam Nutr Res 74: 129136.

17. Lobo RA, 2003 Homocysteine in women's health. Menopause 10: 271-273.

18. Giltay EJ, Verhoef P, Gooren LJ, Geleijnse JM, Schouten EG, Stehouwer CD, 2003 Oral and transdermal estrogens both lower plasma total homocysteine in male-to-female transsexuals. Atherosclerosis 168: 139146.

19. Marchesoni D, Driul L, Plaino L, Villani MT, Becagli L, Mozzanega B, 2003 Menopause rather than estrogen modifies plasma homocysteine levels. Int J Gynaecol Obstet 81: 293-297.

20. Christodoulakos G, Panoulis C, Rizos D, Moustakarias T, Phocas I, Creatsas G, 2001 Homocysteine and folate levels in postmenopausal women. Maturitas 39: 161-167.

21. Giltay EJ, Hoogeveen EK, Elbers JM, Gooren LJ, Asscheman H, Stehouwer CD, 1998 Effects of sex steroids on plasma total homocysteine levels: a study in transsexual males and females. J Clin Endocrinol Metab 83: 550-553.

22. Cagnacci A, Malmusi S, Zanni AL, Alessandrini C, Caretto S, Volpe A, 2004 Comparison of the effect of oral and transdermal hormone therapy on fasting and postmethionine homocysteine levels. Fertil Steril 81: 99-103.

23. Anderson GL, Limacher M, Assaf AR, et al, 2004 Effects of conjugated equine estrogen in postmenopausal women with hysterectomy: the Women's Health Initiative randomized controlled trial. JAMA 291: 17011012.

24. Hak AE, Polderman KH, Westendorp IC, et al, 2000 Increased plasma homocysteine after menopause. Atherosclerosis 149: 163-168.

25. Tallova J, Tomandl J, Bicikova M, Hill M, 1999 Changes of plasma total homocysteine levels during the menstrual cycle. Eur J Clin Invest 29: 1041-1044.

26. Morris MS, Jacques PF, Rosenberg IH, et al, 2000 Serum total homocysteine concentration is related to self-reported heart attack or stroke history among men 
and women in the NHANES III. J Nutr 130: 3073-3076.

27. Wouters MG, Moorrees MT, van der Mooren MJ, et al, 1995 Plasma homocysteine and menopausal status. Eur J Clin Invest 25: 801-805.

28. Andersson A, Brattstrom L, Israelsson B, Isaksson A, Hamfelt A, Hultberg B, 1992 Plasma homocysteine before and after methionine loading with regard to age, gender, and menopausal status. Eur J Clin Invest 22: 79-87.

29. van Baal WM, Smolders RG, van der Mooren MJ, Teerlink T, Kenemans P, 1999 Hormone replacement therapy and plasma homocysteine levels. Obstet Gynecol 94: 485-491.

30. Evio S, Tiitinen A, Turpeinen U, Ylikorkala O, 2000 Failure of the combination of sequential oral and transdermal estradiol plus norethisterone acetate to affect plasma homocysteine levels. Fertil Steril 74: 1080-1083.

31. Smolders RG, van der Mooren MJ, Teerlink T, et al, 2003 A randomized placebo-controlled study of the effect of transdermal vs. oral estradiol with or without gestodene on homocysteine levels. Fertil Steril 79: 261267.

32. Chiantera V, Sarti CD, Fornaro F, et al, 2003 Longterm effects of oral and transdermal hormone replacement therapy on plasma homocysteine levels. Menopause 10: 286-291.

33. Christodoulakos G, Lambrinoudaki I, Panoulis C, Pa- padias C, Kouskouni E, Creatsas G, 2004 Effect of Hormone Replacement Therapy, tibolone and raloxifene on serum lipids, apolipoprotein $\mathrm{A}_{1}$, apolipoprotein B and lipoprotein $(\alpha)$ in Greek postmenopausal women. Gynecol Endocrinol 18: 244-257.

34. Mijatovic V, Kenemans P, Netelenbos C, et al, 1998 Postmenopausal oral 17beta-estradiol continuously combined with dydrogesterone reduces fasting serum homocysteine levels. Fertil Steril 69: 876-882.

35. Ventura P, Cagnacci A, Malmusi S, et al, 2001 Continuous combined hormone replacement therapy with oral 17beta-estradiol and norethisterone acetate improves homocysteine metabolism in postmenopausal women. Menopause 8: 252-258.

36. Kaleli B, Yildirim B, Demir S, Alatas E, 2003 Effects of low-dose 17-beta-estradiol plus norethisterone acetate and tibolone on fasting plasma homocysteine levels in postmenopausal women. Acta Obstet Gynecol Scand 82: 1107-1111.

37. Christodoulakos G, Lambrinoudaki I, Panoulis C, Rizos D, Coutoukos J, Creatsas G, 2003 Effect of raloxifene, estrogen, and hormone replacement therapy on serum homocysteine levels in postmenopausal women. Fertil Steril 79: 455-456.

38. Moustapha A, Robinson K, 1999 Homocysteine: an emerging age-related cardiovascular risk factor. Geriatrics 54: 49-51. 